\title{
EFEKTIVITAS LAMPU LED CELUP SEBAGAI LAMPU HAULING PADA BAGAN PERAHU
}

\author{
Effectiveness of Submersible LED Light as Hauling Lamp on Boat Liftnet
}

\author{
Oleh: \\ M. Iqbal Himam ${ }^{1 *}$, Wazir Mawardi ${ }^{2}$, Diniah ${ }^{2}$, Zulkarnain ${ }^{2}$ \\ ${ }^{1}$ Mahasiswa Magister Program Studi Teknologi Perikanan Laut, Sekolah Pascasarjana IPB \\ ${ }^{2}$ Staf Pengajar Departemen Pemanfaatan Sumberdaya Perikanan, FPIK-IPB \\ *Korespondensi: iqbal010285@gmail.com
}

\begin{abstract}
ABSTRAK
Bagan perahu merupakan alat tangkap yang paling populer di Desa Lhokseudu Kecamatan Leupung Kabupaten Aceh Besar. Nelayan bagan perahu menggunakan lampu neon putih yang dioperasikan di atas permukaan air sebagai pemikat ikan pada saat operasi penangkapan ikan. Beberapa penelitian telah membuktikan bahwa lampu celup bawah air bisa menghasilkan lebih banyak ikan tangkapan. Di sisi lain, perkembangan teknologi telah menemukan lampu LED (light emitting diode). Lampu LED bisa memancarkan cahaya yang lebih terang, dengan input energi lebih kecil dibandingkan dengan lampu neon. Penelitian ini bertujuan untuk mengetahui efektivitas lampu LED celup sebagai lampu hauling pada bagan perahu. Penelitian dilakukan di Desa Lhokseudu sebanyak 15 trip mulai 13 Mei hingga 13 Juni 2016. Pengumpulan data dilakukan dengan menggunakan metode experimental fishing menggunakan dua buah bagan perahu. Satu bagan perahu menggunakan lampu LED celup sebagai lampu hauling dan bagan perahu lainnya menggunakan lampu hauling nelayan sebagai bagan kontrol. Parameter yang diamati adalah berat hasil tangkapan per trip dari kedua bagan untuk dibandingkan. Penelitian ini menyimpulkan bahwa ikan dominan hasil tangkapan bagan perahu di Lhokseudu adalah Rastrelliger kanagurta, Selaroides sp, dan Sardinella sp. Efektivitas lampu hauling LED celup 132,09\% lebih baik dari pada lampu hauling pada bagan kontrol. Hasil uji t pada total tangkapan menunjukkan perbedaan yang signifikan dengan nilai $\mathrm{P}=1,8 \times 10^{-3}$ (kurang dari 0,05 ) pada tingkat kepercayaan $95 \%$.
\end{abstract}

Kata kunci: bagan, lampu hauling, lampu LED celup, Lhokseudu.

\begin{abstract}
Boat liftnet is the most popular fishing gear in Lhokseudu, Aceh Besar District. The boat liftnets use white fluorescent lights that are operated above the water surface. Several researches have proven that submersed lights can produce more catches. In additional, technological developments have discovered LED (light emitting diode) lamp. LED lamps are able to emit brighter light with smaller energy inputs compared with fluorescent lamps. This research aimed to determine the effectiveness of submersed LED lamps as hauling lamp on a boat liftnet. The research was conducted in Lhokseudu on 15 trips starting from 13 May until 13 June 2016. Data was collected using experimental fishing method using two boat liftnets. One boat used a submersed LED lamp as hauling lamp and the other one used the hauling lamp of the fisherman as the control liftnet. The parameters observed were the weight of catch per trip of the two liftnets to be compared. This research concluded that the dominant catch of boat liftnets in Lhokseudu are Rastrelliger kanagurta, Selaroides sp, and Sardinella sp. The effectiveness of submersed LED hauling lamp was 132,09\% better than the hauling lamp of control liftnet. The result of t-test on total catches shows a significant difference with $P$-value $=1.8 \times 10^{3}$ (less than 0,05) at 95\% confidence level.
\end{abstract}


Keywords: hauling lamp, Lhokseudu,liftnet, submersible LED light.

\section{PENDAHULUAN}

Bagan perahu merupakan salah satu jenis alat tangkap yang digunakan oleh nelayan di Desa Lhokseudu, Kecamatan Leupung Kabupaten Aceh Besar. Nelayan bagan menggunakan lampu neon berwarna putih sebagai pemikat ikan pada saat operasi penangkapan ikan. Lampu berfungsi sebagai alat bantu pemikat jenis-jenis ikan yang bersifat fototaksis positif, sehingga nelayan mudah melakukan penangkapan (Yuda 2012). Berbagai sumber cahaya dapat digunakan sebagai pemikat ikan pada bagan. Sumber cahaya yang paling populer sebelum tahun 2010 adalah petromaks dengan bahan bakar minyak tanah. Namun sejak pencabutan subsidi pemerintah terhadap minyak tanah pada tahun 2010, petromaks dianggap tidak lagi ekonomis (Syafrie 2012). Nelayan bagan pada kondisi ini terpaksa beralih menggunakan lampu dengan sumber energi listrik untuk menghasilkan cahaya pemikat ikan. Jenis lampu yang umum digunakan nelayan bagan perahu di Desa Lhokseudu adalah lampu neon. Berdasarkan fungsinya lampu yang dipakai pada bagan perahu terbagi menjadi lampu kerja, lampu pemikat ikan dan lampu hauling. Lampu kerja berada di atas dek dan berfungsi memberi penerangan pada area kerja anak buah kapal (ABK). Lampu pemikat ikan berfungsi untuk menarik perhatian ikan agar mendekati bagan. Adapun lampu hauling berfungsi untuk mengkonsentrasikan dan menjaga ikan tetap di atas cakupan jaring (catchable area) saat proses hauling, sehingga sangat menentukan keberhasilan operasi bagan perahu.

Penelitian mengenai lampu pada perikanan bagan telah dilakukan oleh beberapa peneliti, diantaranya penelitian yang dilakukan Notanubun dan Patty (2010) membahas perbedaan penggunaan intensitas cahaya lampu terhadap hasil tangkapan bagan apung di Perairan Selat Rosenberg Kabupaten Maluku Tenggara. Penelitian tersebut mengungkap bahwa lampu celup neon 36 watt dan 54 watt menghasilkan lebih banyak hasil tangkapan dibandingkan lampu lampu petromaks dan lampu celup neon 18 watt. Gustaman et al. (2012) meneliti efektivitas warna cahaya lampu bagan tancap di perairan Sungsang Sumatera Selatan dan menyimpulkan bahwa cahaya putih merupakan cahaya paling efektif untuk menangkap ikan pelagis kecil dibandingkan cahaya warna kuning dan biru. Syafrie (2012) mengujicobakan lampu tabung yang dicelupkan ke dalam air di Teluk Pelabuhanratu dengan hasil yang lebih baik dari lampu standar nelayan. Yulianto (2015) menyatakan bahwa lampu neon yang dipasang pada bagian bawah rumah bagan masih kurang efektif. Hal ini disebabkan pemudaran cahaya yang masuk ke dalam air.

Penelitian mengenai light fishing tidak hanya menarik minat para peneliti di bidang perikanan. Beberapa peneliti dari bidang lain, seperti fisika dan bidang elektro-pun telah meneliti light fishing. Fitria et al. (2013) meneliti respon optimal fungsi penglihatan ikan terhadap panjang gelombang dan intensitas cahaya tampak. Adapun peneliti dari bidang elektro, Setiawan et al. (2015) membahas pengaruh medium perambatan terhadap intensitas cahaya.

Pada sisi lain, perkembangan teknologi telah menemukan lampu berbasis LED (light emitting diode). Lampu LED dapat memancarkan cahaya yang lebih terang, dengan input energi yang lebih kecil. Jenis Lampu ini memerlukan arus searah (DC) sebagai pasokan daya. Arus listrik DC bisa diperoleh dari baterai atau dengan adaptor. Thenu et al. (2013) dan Julian (2014) menyatakan bahwa penggunaan lampu LED pada bagan tancap di Teluk Pelabuhanratu memberikan hasil tangkapan yang lebih banyak dari pada lampu neon nelayan. Penelitian ini bertujuan untuk menentukan efektivitas lampu LED celup sebagai lampu hauling pada bagan perahu di Desa Lhokseudu, Aceh Besar. 


\section{METODE PENELITIAN}

Penelitian ini dilaksanakan di Desa Lhokseudu menggunakan bagan milik masyarakat setempat (Gambar 1). Peta lokasi penelitian dapat dilihat pada Gambar 2. Pelaksanaan penelitian selama 15 hari operasi penangkapan ikan, yang dimulai pada 13 Mei 2016 hingga 13 Juni 2016. Penelitian ini menggunakan lampu LED celup (Gambar 3) yang telah dirancang bangun sebelumnya. Jenis LED yang digunakan adalah jenis ultra bright dip $5 \mathrm{~mm}$. Warna LED yang digunakan adalah putih, mengacu pada penelitian Gustaman et al. (2012). Setiap individu LED dapat menyala optimal pada tegangan 3,2-3,4 volt dan arus $40 \mathrm{~mA}$. Selanjutnya 3 lampu LED dan resistor 46,79 ohm dirangkai secara seri agar sesuai dengan tegangan sumber 12 Volt. Sebanyak 104 Rangkaian seri LED dirangkai secara paralel dan disusun pada kerangka dari pipa PVC berdiameter 5 inchi. Keseluruhan rangkaian lampu mengkonsumsi daya 49,92 watt. Konsumsi daya lampu LED hasil rancang bangun mendekati jumlah konsumsi daya lampu hauling pada bagan kontrol sebesar 54 watt (3 x 18 watt).

Pengambilan data dilakukan dengan metode experimental fishing dengan mengoperasikan dua unit bagan. Perbedaan kedua bagan adalah pada penggunaan lampu hauling. Lampu hauling pada bagan kontrol berupa tiga buah lampu neon 18 watt yang dipasang di bawah dek. Lampu hauling pada bagan percobaan berupa lampu LED yang dicelupkan satu meter di bawah permukaan air. Data yang diambil adalah jumlah hasil tangkapan pada masing-masing bagan dengan pengulangan sebanyak 15 kali (15 trip). Pengambilan data dilakukan terhadap ikan hasil tangkapan dengan parameter meliputi jenis ikan dan total berat per jenis ikan.

Analisis data yang digunakan adalah metode deskriptif komparatif. Data tersebut diolah secara komparatif dengan menggunakan uji nilai tengah (uji t atau t-student).

Uji nilai tengah dilakukan untuk mengetahui perbedaan pengaruh penggunaan lampu hauling kontrol dan lampu hauling LED celup terhadap hasil tangkapan. Uji nilai tengah dilakukan dengan asumsi bahwa ragam populasi adalah sama dengan menggunakan rumus berikut (Walpole 1995) :

Hipotesis yang digunakan adalah :

$H_{0} H_{1} H_{2}$ Tidak ada perbedaan pengaruh penggunaan lampu neon dengan lampu LED celup terhadap hasil tangkapan.

$H_{1} \mid H_{1} H_{2}$ Ada perbedaan pengaruh penggunaan lampu neon dengan lampu LED celup terhadap hasil tangkapan.

Keterangan :

$\mu_{1}$ : Rata-rata hasil tangkapan menggunakan lampu lampu standar,

$\mu_{2}$ : Rata-rata hasil tangkapan menggunakan lampu LED celup. 


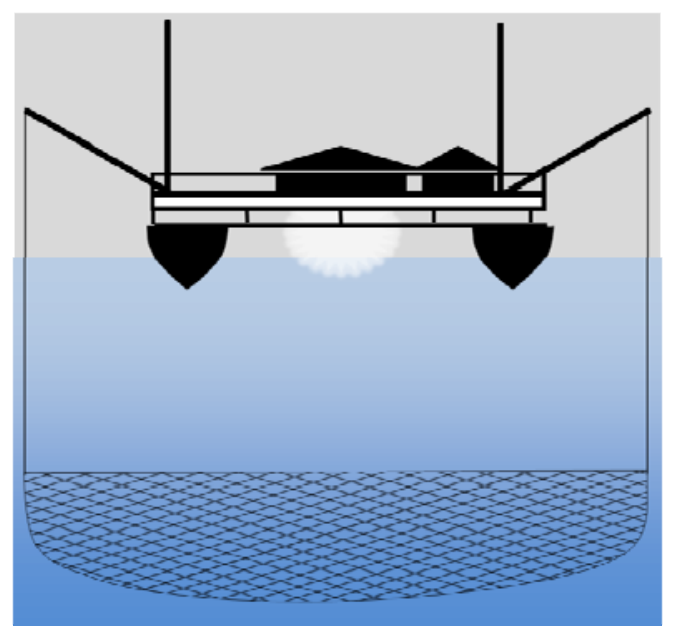

Gambar 1 Bagan apung (nama daerah: Palong)

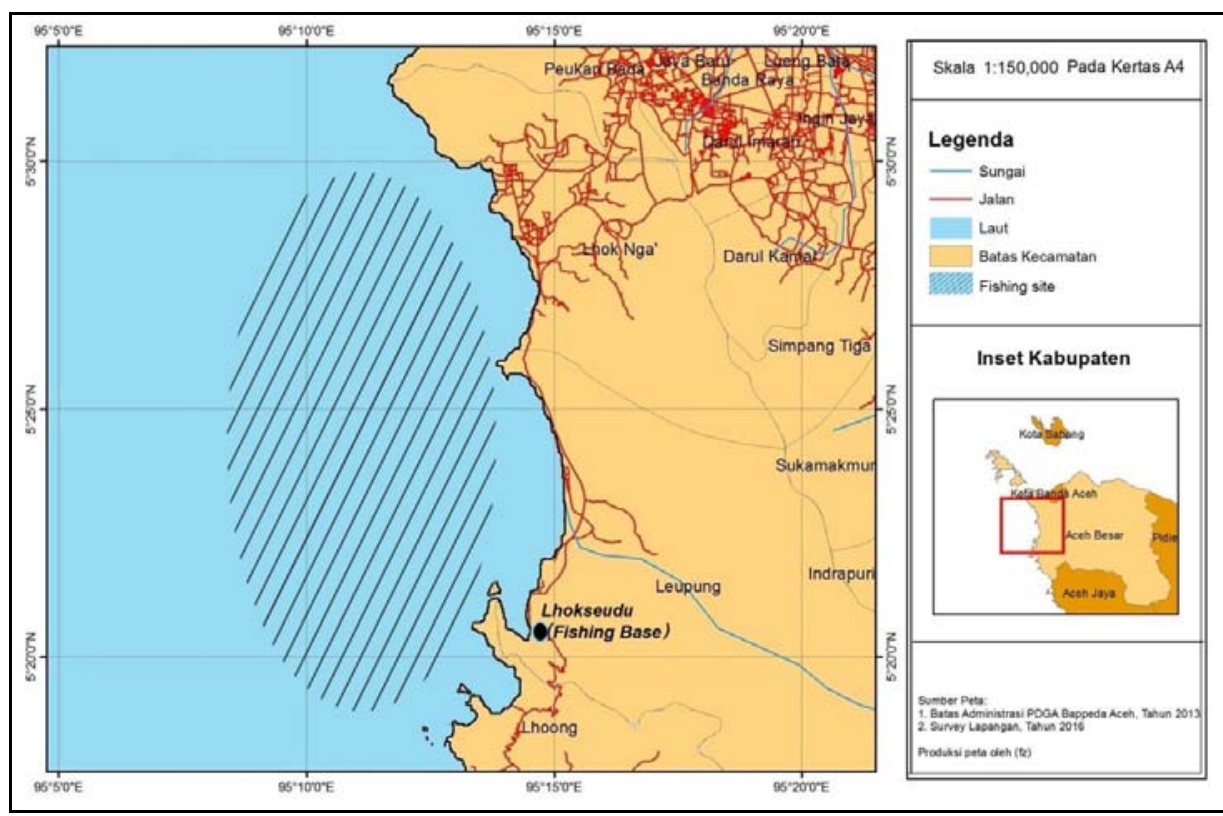

Gambar 2 Peta lokasi penelitian

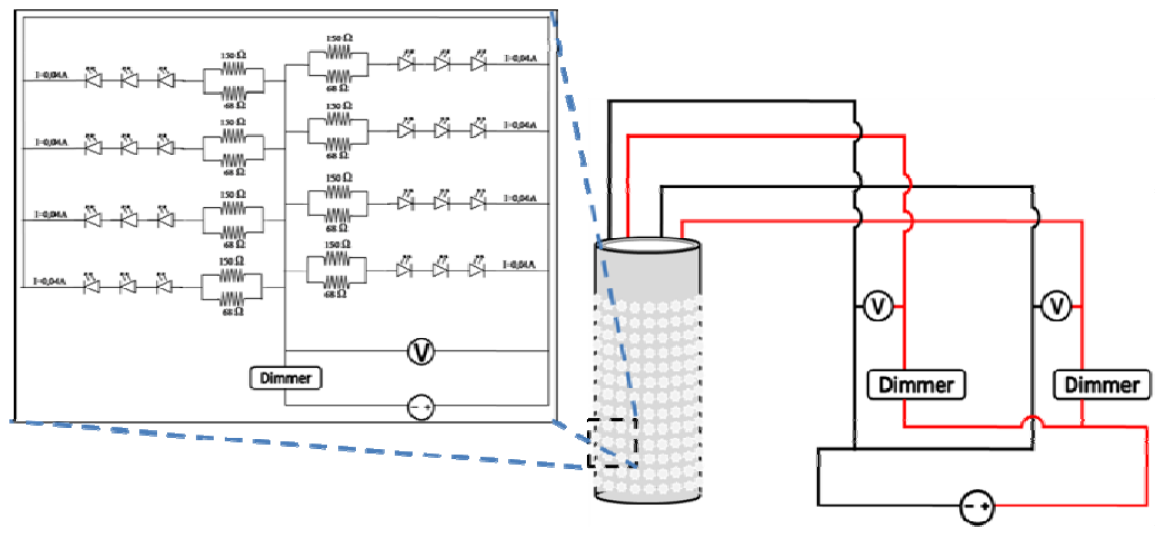

Gambar 3 Lampu LED celup 


\section{HASIL DAN PEMBAHASAN}

\section{Bagan Perahu di Lhokseudu}

Desa Lhokseudu terletak di Kecamatan Leupung Kabupaten Aceh Besar. Leupung mencatat hasil perikanan tangkap pada tahun 2014 sebesar 775,3 ton (BPS 2015). Alat tangkap yang digunakan di wilayah ini adalah bagan sebanyak 18 unit, Pukat Cincin (purse seine) sebanyak 5 unit, jaring insang (gill net) sebanyak 4 unit, dan pancing ulur (handline) 3 unit. Bagan Lhokseudu menggunakan dua buah perahu sebagai pengapung dengan bahan konstruksi utama menggunakan kayu, berbeda dengan bagan di perairan Jawa yang menggunakan bambu. Aktifitas operasi bagan perahu di perairan Lhokseudu hanya dapat dilaksanakan pada musim angin timur, sedangkan pada musim angin barat dimanfaatkan nelayan bagan perahu untuk memperbaiki unit alat tangkap.

Pengoperasian bagan perahu di Lhokseudu dimulai dengan menyalakan seluruh lampu sejak senja (sekitar 19:00 WIB). Tahap selanjutnya adalah menunggu ikan berkumpul di sekitar bagan. Sebelum menurunkan jaring, Pawang atau fishing master memantau kepadatan ikan sambil sesekali mengecek keberadaan ikan predator dengan menggunakan pancing aset (pancing kotrek/pancing tangan). Apabila didapati ikan predator, seperti kurisi, maka pawang memutuskan untuk pindah titik pengoperasian bagan apung. Tahap pengumpulan ikan ini merupakan proses terlama dalam pengoperasian bagan perahu di Lhokseudu, sehingga dimanfaatkan ABK untuk memancing. Tahap penurunan jaring dilakukan lewat tengah malam (sekitar 01:00 WIB) dimulai dengan mematikan lampu kerja. Lampu pemanggil mulai dikurangi secara bertahap hingga menyisakan lampu hauling pada pukul 02:00 WIB. Tahap hauling dimulai pada pukul 02:30 WIB yang diikuti dengan penyortiran dan penurunan jaring kembali. Setiap satu trip dapat dilakukan tiga kali hauling dengan interval antar hauling berkisar 1-1,5 jam tergantung durasi proses sortir. Secara teknis keunggulan lampu LED celup dibandingkan dengan lampu kontrol adalah hemat energi, mudah dikontrol, aman, dan awet (Li dan Jing 2013). Diperlukan kajian lebih lanjut aspek ekonomi dan kelayakan usaha agar dapat diaplikasikan oleh nelayan.

\section{Komposisi Hasil Tangkapan}

Hasil tangkapan bagan apung selama penelitian terdiri dari ikan pelagis kecil yang berenang dalam gerombolan. Jenis ikan yang dominan tertangkap adalah ikan kembung (Rastrelliger sp), selar (Selaroides sp), dan tembang (Sardinella fimbriata). Selain jenis dominan tersebut, tertangkap juga ikan lain dalam porsi kecil yang terdiri dari cumi-cumi (Loligo sp), pepetek (Leiognathus sp), dan teri (Stolephorus sp). Hasil tangkapan secara lengkap disajikan pada Lampiran. Jumlah hasil tangkapan bagan kontrol berkisar antara 150-330 Kg/trip. Total hasil tangkapan selama 15 trip sebanyak 3.630 Kg. Jenis hasil tangkapan dengan jumlah terbanyak adalah ikan kembung (Rastrelliger kanagurta) dengan total tangkapan $1.520 \mathrm{Kg}$ atau mencapai $41,87 \%$.

Jumlah hasil tangkapan bagan dengan lampu LED celup berkisar antara 210-450 Kg/trip. Total hasil tangkapan selama 15 trip sebanyak $4.800 \mathrm{Kg}$. Jenis hasil tangkapan dengan jumlah terbanyak adalah ikan kembung (Rastrelliger kanagurta) dengan total tangkapan $1.870 \mathrm{Kg}$ atau mencapai 38,96\%. Perbandingan rata-rata berat hasil tangkapan per trip antara bagan kontrol dengan bagan LED celup tersaji pada Gambar 4. Kriswantoro dan Sunyoto (1986) disadur oleh Syafrie (2012) menyatakan bahwa penyebaran ikan kembung sangat luas, meliputi hampir seluruh perairan Indonesia. Konsentrasi terbesar ikan kembung lelaki terdapat di Barat Sumatera, Laut Jawa, Selat Malaka, Kalimantan Selatan, Sulawesi Selatan, Muna-Buton, dan perairan Arafura. 


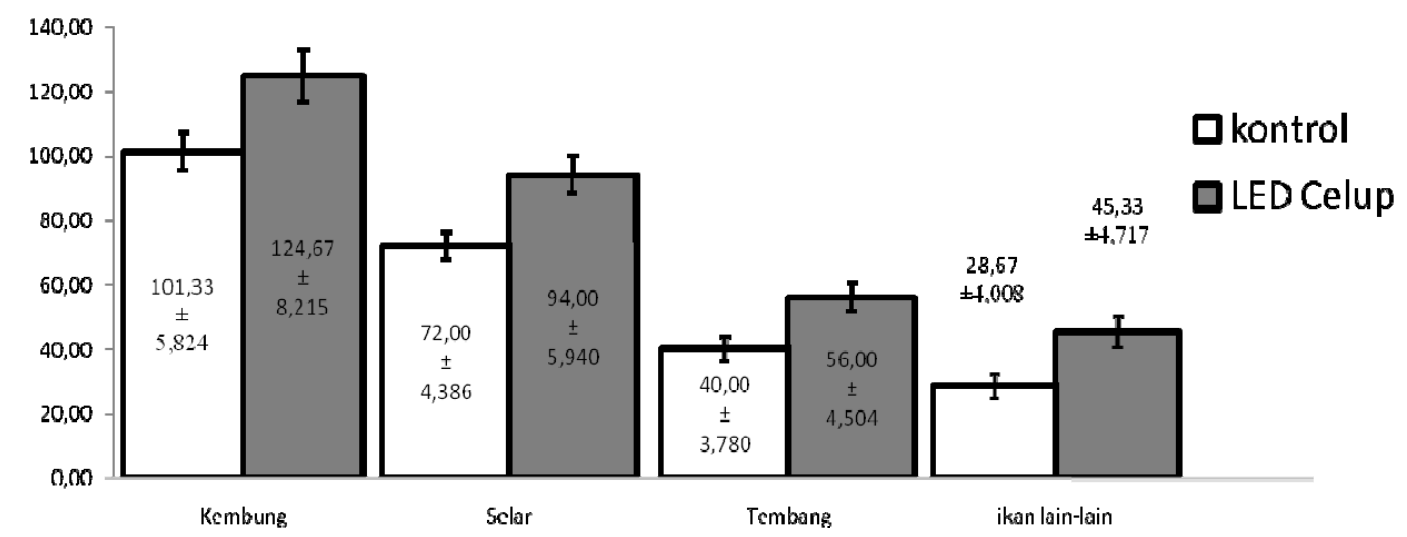

Gambar 4 Rata-rata jumlah hasil tangkapan per trip

Ikan selar (Selaroides sp) menjadi hasil tangkapan dominan kedua setelah ikan kembung. Ikan selar dapat ditemukan dari laut lepas sampai perairan pantai dan desa pada hampir seluruh wilayah perairan Indonesia. Jenis makanan selar adalah zooplankton, benthos, larva ikan dan juga ikan-ikan kecil lainnya yang sesuai dengan bukaan mulut ikan tersebut. Keberadaan selar yang tertangkap di bagan berkaitan erat dengan aktivitasnya ketika mencari makan di bawah bagan. Selar muncul di permukaan perairan di bawah sumber cahaya untuk melakukan aktivitas makan (Tupamahu et al. 2001). Tembang (Sardinella sp) merupakan ikan dominan ketiga yang keberadaannya di sekitar bagan dikarenakan jenis ikan ini tertarik oleh cahaya lampu dengan iluminasi antara 10-100 lux (Tupamahu et al. 2001). Jumlah teri yang tertangkap pada penelitian ini terhitung sangat kecil. Hal ini disebabkan penelitian dilaksanakan saat tidak berlangsung musim teri.

Lampu hauling LED dioperasikan dengan dicelupkan ke dalam air untuk mengurangi kerugian cahaya akibat pemantulan dan pembiasan cahaya oleh permukaan air. Pemantulan cahaya pada permukaan air menyebabkan penetrasi cahaya ke dalam air semakin berkurang, sedangkan pembiasan cahaya pada permukaan air bergelombang akan menyebabkan arah cahaya berubah-ubah. Baskoro dan Taurusman (2011) menyatakan bahwa cahaya yang berubah-ubah pada akhirnya akan menimbulkan sinar yang menakuti ikan.

Komposisi hasil tangkapan bagan kontrol dan bagan dengan lampu LED celup tidak menunjukkan perbedaan berarti (Gambar 5). Jenis ikan dominan dari kedua bagan juga sama, yaitu ikan kembung, berturut-turut diikuti selar, tembang, dan ikan campuran dalam jumlah kecil. Kemiripan komposisi hasil tangkapan ini disebabkan penggunaan warna yang sama, yaitu putih. Kesamaan warna menghasilkan kesamaan panjang gelombang cahaya. Syafaat (2014) menyatakan bahwa panjang gelombang mempengaruhi penetrasi cahaya lampu dan berpengaruh pula terhadap tingkat efek fototaksis sebagai respon ikan. Lampu menciptakan area terang dan menyebabkan sebaran plankton terkonsentrasi di sekitar bagan. Plankton menyukai perairan yang mendapat penerangan (Basmi 1995). Kelimpahan sebaran plankton pada akhirnya akan mengundang organisme lain mendekat ke bagan. Jenis dan komposisi hasil tangkapan atau konsentrasi gerombolan ikan berbeda-beda untuk setiap jenisnya. Pada perikanan bagan ikan teri membentuk gerombolan pada kedalaman 0-5 meter yaitu pada kisaran iluminasi cahaya 80-120 lux dan untuk ikan kembung, ikan layang dan tembang berada pada kisaran kedalaman 10-20 meter yaitu pada kisaran intensitas 5-10 lux, sedangkan cumi-cumi berada pada daerah bayang-bayang (Sudirman 2003). 


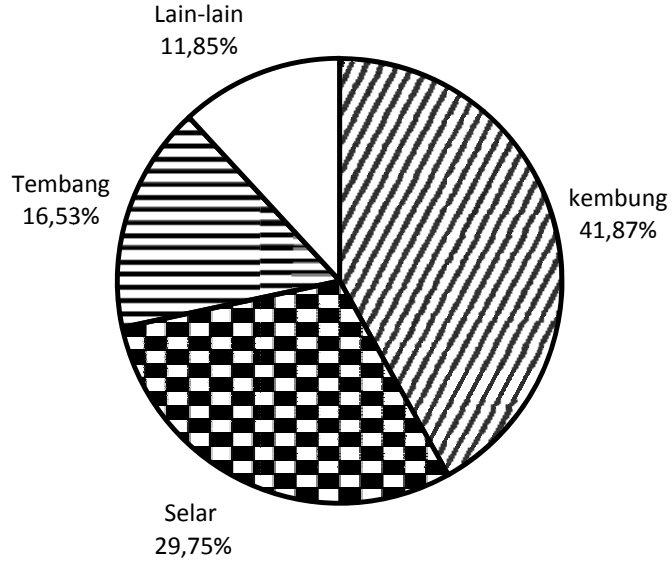

(a) Bagan kontrol

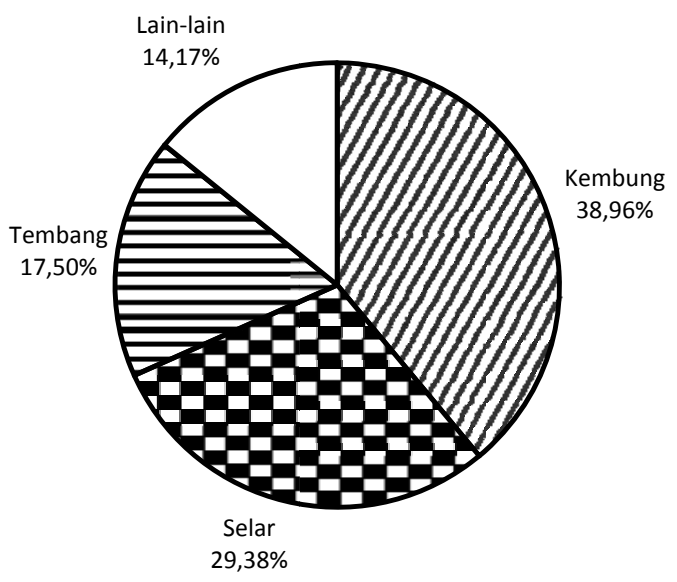

(b) LED celup

Gambar 5 Komposisi hasil tangkapan ikan pada bagan perahu

Efektivitas adalah tingkat pencapaian hasil terhadap tujuan yang telah ditetapkan dan dinyatakan dalam persen (Gibson et al. 1990). Efektivitas penangkapan ikan dapat diartikan sebagai kemampuan alat dan atau metode untuk mendapatkan hasil tangkapan optimum sesuai dengan tujuan penangkapan (Baskoro et al. 2006). Jika jumlah hasil tangkapan bagan kontrol dijadikan sebagai target pembanding, maka dapat dikatakan bahwa lampu hauling LED celup memiliki efektivitas sebesar 132,09\% dibandingkan lampu neon (kontrol). Efektivitas lampu hauling LED celup tidak terlepas dari keunggulan lampu itu sendiri. Lampu LED diketahui dapat memancarkan cahaya yang lebih terang dari lampu neon sekalipun dengan jumlah konsumsi daya yang sama. Pemilihan adaptor untuk merubah arus AC dari genset menjadi DC menghasilkan tegangan yang konstan, sehingga iluminasi LED lebih stabil.

Berdasarkan hasil penelitian ini, efektivitas bagan dengan LED Celup berkisar antara 112,5150\% dengan rata-rata 132,09\% lebih besar dari pada bagan kontrol. Hasil ini lebih tinggi dari pada penelitian Thenu et al. (2013) sebesar 120,69\% dan oleh Julian (2014) sebesar 130,34\% dari hasil tangkapan lampu neon, yang mana keduanya melakukan penelitian di Teluk Palabuhanratu. Hasil analisis statistik Uji T (T-Student) dengan kategori unequal variances menunjukkan perbedaan nyata pada rata-rata jumlah hasil tangkapan antara bagan kontrol dan bagan dengan lampu LED celup dengan Nilai P-value yang didapatkan adalah $1,8 \times 10^{-3}$ (kurang dari 0,05). Jumlah hasil tangkapan lampu hauling LED celup lebih besar dibandingkan lampu kontrol pada taraf kepercayaan 95\%.

\section{KESIMPULAN DAN SARAN}

Hasil penelitian ini dapat disimpulkan bahwa jenis ikan hasil tangkapan dominan bagan perahu di Lhokseudu adalah kembung, selar, dan tembang. Efektivitas bagan dengan lampu hauling LED celup 132,09\% lebih baik dibandingkan dengan bagan kontrol. Hasil uji-t terhadap jumlah hasil tangkapan menunjukkan perbedaan nyata dengan nilai $\mathrm{P}$-value $=1,8 \times 10^{-3}$ (kurang dari 0,05 ) pada taraf kepercayaan 95\%.

Berdasarkan penelitian ini dapat disarankan untuk melakukan penelitian sepanjang musim penangkapan untuk mendapatkan data musim ikan spesies tertentu. Selain itu perlu dilakukan penelitian lebih lanjut mengenai aspek ekonomi dan kelayakan usaha penangkapan dengan lampu LED celup agar dapat diaplikasikan oleh nelayan. 


\section{DAFTAR PUSTAKA}

Baskoro MS, Telussa RF, Purwangka F. 2006. Efektivitas bagan motor di Perairan Waai, Pulau Ambon. Di dalam Sondita MFA, Sobari MP, Simbolon D, Puspito G, Pane AB, Editor. Menuju Paradigma Perikanan Tangkap Yang Bertanggung Jawab dalam Mendukung Revitalisasi Perikanan. Seminar Perikanan Tangkap: 2006 Agustus: Bogor (ID), Departemen Pemanfaatan Sumberdaya Perikanan Institut Pertanian Bogor. hlm 115-121.

Baskoro MS, Taurusman AA. 2011. Tingkah laku ikan: hubungannya dengan ilmu dan teknologi perikanan tangkap. Bandung. $258 \mathrm{hal}$

Basmi J. 1995. Planktonologi : Produksi Primer. Bogor (ID): Fakultas Perikanan Institut Pertanian Bogor.

[BPS] Badan Pusat Statistik. 2015. Aceh Besar dalam angka. Aceh Besar (ID): BPS Kabupaten Aceh Besar.

Fitria F, Ratnayanti W, Anggono T. 2013. Penentuan respon optimal fungsi penglihatan ikan terhadap panjang gelombang dan intensitas cahaya tampak. Jurnal Fisika dan Terapannya. $1(4): 41-46$

Gustaman G, Fauziyah, Isnaini. 2012. Efektifitas perbedaan warna cahaya lampu terhadap hasil tangkapan bagan tancap di Perairan Sungsang Sumatera Selatan. Maspari Jurnal. 4(1): 92-102.

Gibson JL, Ivancevich JM, Donnelly JH. 1990. Organisasi dan Manajemen: Perilaku, Struktur, Proses.Wahid D. Jakarta (ID): Erlangga. Terjemahan dari: Organizations. Behaviour, Structure, Processes.

Julian D. 2014. Uji coba penangkapan ikan dengan bagan tancap menggunakan lampu LED (light emitting diode). [Skripsi]. Bogor (ID): Institut Pertanian Bogor.

Li TH, Jing X. 2013. Research on LED fishing light. Research Journal of Applied Sciences, Engineering and Technology. 5(16). 4138-4141.

Notanubun J, Patty W. 2010. Perbedaan penggunaan intensitas cahaya lampu terhadap hasil tangkapan bagan apung di perairan Selat Rosenberg Kabupaten Maluku Tenggara Kepulauan Kei. Jurnal Perikanan dan Kelautan. VI(3):134-140.

Setiawan F, Sulistiyanti R, Sadnowo A. 2015. Analisis pengaruh medium perambatan terhadap intensitas cahaya lacuba (lampu celup bawah air). Electrician Jurnal Rekayasa dan Teknologi Elektro. 9(1):21-29

Sudirman. 2003. Analisis tingkah laku ikan untuk mewujudkan teknologi ramah lingkungan dalam proses penangkapan pada bagan rambo [Disertasi]. Bogor (ID) : Sekolah Pascasarjana IPB.

Syafaat APP. 2014. Optimasi panjang gelombang cahaya lampu celup dalam air sebagai alat bantu penangkapan ikan di bagan apung Perairan Barru, Sulawesi Selatan. [Skripsi]. Bogor (ID: Institut Pertanian Bogor.

Syafrie H. 2012. Efektifitas lampu tabung pada perikanan bagan. [Thesis]. Bogor (ID): Sekolah Pasca Sarjana IPB.

Thenu IM, Puspito G, Martasuganda S. 2013. Penggunaan light emitting diode pada lampu celup bagan. Marine Fisheries. 4(2):141-151

Tupamahu A, Baskoro MS, Jaya I, Monintja DR. 2001. Komparasi adaptasi retina ikan tembang (Sardinella fimbriata) dan selar (Selar crumenopthalmus) yang tertarik dengan cahaya lampu. Buletin PSP. 10(1):65-74 
Walpole RE. 1995. Pengantar Statistika: Edisi Ketiga. Sumantri B. Jakarta (ID): PT Gramedia Pustaka Utama. Terjemahan dari: Introduction To Statistics . Third edition.

Yuda LK. 2012. Tingkat keramahan lingkungan alat tangkap bagan di Perairan Palabuhanratu, Kabupaten Sukabumi. Jurnal Perikanan dan Kelautan Vol. 3. ISSN: 2088-3137.

Yulianto E. 2015. Rekayasa Unit Lampu LED Bawah Air untuk Riset Tingkah Laku Ikan [Tesis]. Bogor (ID): Sekolah Pascasarjana IPB. 